\title{
Preferência e percepções do tutor pelo modo de transporte dos animais de companhia em voos comerciais
}

\author{
Tutor preference and perception for the type of pet animal transportation on commercial flights \\ Preferencia y percepciones del tutor por el modo de transporte de los animales de compañía en \\ vuelos comerciales
}

Recebido: 20/12/2020 | Revisado: 27/12/2020 | Aceito: 30/12/2020 | Publicado: 03/01/2021

\author{
Daniel Rodrigues Dutra \\ ORCID: https://orcid.org/0000-0001-5435-243X \\ Universidade Estadual Paulista "Júlio de Mesquita Filho", Brasil \\ E-mail: danielrdutra@hotmail.com \\ Juliana Stephani de Souza \\ ORCID: https://orcid.org/0000-0003-4913-9823 \\ PETFriendly Turismo, Brasil \\ E-mail: justephani@petfriendlyturismo.com.br \\ Erick Alonso Villegas-Cayllahua \\ ORCID: https://orcid.org/0000-0003-0939-9305 \\ Universidade Estadual Paulista "Júlio de Mesquita Filho", Brasil \\ E-mail: evillegasc22@gmail.com \\ Juliana Lolli Malagoli de Mello \\ ORCID: https://orcid.org/0000-0003-4648-1412 \\ Universidade Estadual Paulista "Júlio de Mesquita Filho", Brasil \\ E-mail: julianalolli@zootecnista.com.br \\ Hirasilva Borba \\ ORCID: https://orcid.org/0000-0001-7057-3945 \\ Universidade Estadual Paulista "Júlio de Mesquita Filho", Brasil \\ E-mail: hirasilva.borba@unesp.br
}

\begin{abstract}
Resumo
Animais de companhia tem sido cada vez mais integrados em atividades familiares. Diante desta tendência, objetivouse avaliar a preferência dos tutores pelas condições de transporte aéreo oferecidas em situação comercial a seus animais (cabine ou porão). Foram ainda avaliadas a preocupação dos tutores em relação ao bem-estar animal, sua insegurança em relação aos serviços de aerotransporte e a importância dada à infraestrutura dos aeroportos. Os dados foram coletados por oito meses, a partir da aplicação de dois questionários. Para o primeiro questionário, foram selecionados 80 tutores, transportando no mínimo um cão ou um gato, entre voos nacionais e internacionais. O segundo questionário foi aplicado a 157 indivíduos que possuíam ao menos um animal de companhia e intenção de embarcá-lo em voos comerciais, onde escalas hedônicas compuseram opções de respostas para cada fator. 58\% dos tutores optaram por embarcar seus pets na cabine de passageiros e $42 \%$ no porão da aeronave. A maioria dos fatores relacionados ao bem-estar animal durante o voo foram considerados "extremamente preocupantes". Os tutores se apresentaram "extremamente inseguros" ao contratar serviços aéreos e consideraram os fatores ligados à infraestrutura aeroportuária "muito importantes" para seus animais. Mereceram destaque a "extrema preocupação" com os maustratos aos animais (74,4\%), a "extrema insegurança" com a possibilidade de extravio dos animais $(76,0 \%)$ e a "muita importância" dada às garantias de bem-estar e segurança dos animais nos aeroportos $(91,1 \%)$. Portanto, conclui-se que os tutores preferem transportar seus animais de companhia na cabine, como forma de garantir o bem-estar animal durante o voo.
\end{abstract}

Palavras-chave: Bem-estar animal; Pets; Transporte aéreo.

\begin{abstract}
Pets have been increasingly integrated into family activities. In view of this tendency, the objective of this study was to assess the preference of tutors for the air transport conditions offered in a commercial situation to their animals (cabin or cargo hold). Tutors' concerns about animal welfare, their insecurity in relation to the air transport services and the importance given to airport infrastructure were also assessed. Data were collected for eight months, by applying two questionnaires. For the first questionnaire, 80 tutors were selected, carrying at least one dog or cat, in both national and international flights. The second questionnaire was applied to 157 individuals who owned at least one pet and intended to board it along on commercial flights, whereas hedonic scales composed response options for
\end{abstract}


each factor. $58 \%$ of tutors chose to board their pets in the passenger cabin and $42 \%$ in the aircraft cargo hold. Most of the factors related to animal welfare during the flight were considered "extremely worrying". Tutors were "extremely insecure" when hiring air services and considered the factors related to the infrastructure of the airports "very important" for their animals. The "extreme concern" with the mistreatment of animals (74.4\%), the "extreme insecurity" with the possibility of extraviation of the animals (76.0\%) and the "great importance" given to guarantees of animal welfare and safety at the airports $(91.1 \%)$ were very relevant in this research. Therefore, it is concluded that tutors prefer to transport their pets in the cabin, as a way to guarantee animal welfare during the flight.

Keywords: Animal welfare; Air transport; Pets.

\section{Resumen}

Los animales domésticos se han integrado cada vez más en las actividades familiares. Ante esta nueva tendencia, el objetivo fue evaluar la preferencia de los tutores por las condiciones de transporte aéreo ofrecidas en situación comercial a sus animales (cabina o bodega). También se evaluaron las preocupaciones de los tutores sobre el bienestar animal, su inseguridad en relación con los servicios de transporte aéreo y la importancia que se le da a la infraestructura aeroportuaria. Los datos se recopilaron durante ocho meses mediante dos cuestionarios. Para el primer cuestionario se seleccionaron 80 tutores, con al menos un perro o un gato, entre vuelos nacionales e internacionales. El segundo cuestionario se aplicó a 157 personas que tenían al menos una mascota y tenían la intención de llevarla en vuelos comerciales, donde escalas hedónicas componeron opciones de respuesta para cada factor. El 58\% de los tutores optaron por embarcar a sus mascotas en la cabina de pasajeros y el $42 \%$ en la bodega del avión. La mayoría de los factores relacionados con el bienestar animal durante el vuelo se consideraron "extremadamente preocupantes". Los tutores se mostraron "extremadamente inseguros" a la hora de contratar servicios aéreos y consideraron los factores relacionados con la infraestructura de los aeropuertos "muy importantes" para sus animales. La "extrema preocupación" por el maltrato a los animales $(74,4 \%)$, la "extrema inseguridad" con la posibilidad de pérdida de animales $(76,0 \%)$ y la "gran importancia" otorgada a las garantías de bienestar y seguridad animal en los aeropuertos $(91,1 \%)$ fueron muy relevantes en esta investigación. Por tanto, se concluye que los tutores prefieren transportar a sus mascotas en cabina, como forma de garantizar el bienestar animal durante el vuelo.

Palabras clave: Bienestar animal; Mascotas; Transporte aéreo.

\section{Introdução}

Com a constante transformação na relação entre o tutor e seu animal de estimação, a presença de animais em aeroportos tem sido cada vez mais frequente. Muitos tutores têm estabelecido um vínculo emocional tão forte com seus animais, considerando-os membros de sua própria família, que acabam por incluí-los em seu planejamento de viagem (Bland, 2013). Entretanto, a forma que com esses animais são transportados nas aeronaves, muitas vezes tratados meramente como bagagens (Bland, 2013), tem suscitado novas discussões e fomentado mudanças nas políticas internas das companhias aéreas.

A falta de legislação específica faz com que cada empresa possua suas próprias regras em relação ao transporte aéreo dos animais de companhia, as quais abarcam limite de peso, tamanho e raças. Apesar de restritivas, tais exigências não levam em consideração o bem-estar animal, conforto, segurança e a saúde do pet em sua totalidade durante o voo, o que por muitas vezes leva a muitos tutores a não se sentirem completamente seguros para embarcar seus animais, devido ao medo e à incerteza do que possa ocorrer durante o traslado.

Algumas empresas, por exemplo, estabelecem altura máxima permitida para as caixas de transporte que serão transportadas junto às cabines nas aeronaves, mas não consideram o fato do animal de médio porte permanecer horas sem se levantar ou se movimentar em seu interior.

Outra situação que merece destaque, refere-se àqueles animais que são despachados como carga viva, sendo transportados sozinhos nos porões das aeronaves, sujeitos a longos períodos de jejum hídrico e alimentar, em ambientes completamente desconhecidos, sem rigoroso controle de temperatura e arrefecimento, e sem quaisquer possibilidades de se movimentarem e interagirem com seus tutores (Collins et al., 2020; Coren, 2012). Sem mencionar o extravio de animais, gerando enormes prejuízos ao animal, em termos de bem-estar físico e psicológico, causando muita insegurança, preocupação e angústia aos tutores. 
Apesar de toda a problemática relatada, o que se tem disponível na literatura científica sobre o tema é muito escasso, e os poucos estudos publicados focam majoritariamente no despacho aéreo de animais de competição e produção (Collins, et al., 2020; Fleming, et al., 2020; Hogan \& Willis, 2009; Bergeron, et al; 2002). Diante disso, buscamos com nosso estudo avaliar a preferência e as percepções dos tutores frente às condições de transporte comercial aéreo oferecidas a seus animais.

\section{Metodologia}

Para composição do presente estudo foi realizada pesquisa quantitativa pelo método survey, por meio da coleta de informações sobre as características de preferência e opiniões dos tutores, utilizando-se dois questionários como instrumentos de pesquisa, com posterior análise estatística dos dados obtidos.

O método survey tem sido amplamente empregado em recentes pesquisas científicas envolvendo a percepção dos tutores sobre o bem-estar e comportamento animal (Escobar-Aguirre et al., 2019; Menchetti et al., 2020; Paolini et al., 2020; Silva et al., 2020). Tratando-se, portanto, de um procedimento cada vez mais aceito pela comunidade científica, ao proporcionar resultados amostrais confiáveis e passíveis de serem extrapolados à população de maneira geral (Miguel et al., 2012).

Os questionários foram aplicados on-line por um período de oito meses (janeiro a agosto de 2019) a tutores que contrataram ou apresentaram interesse nos serviços prestados por empresa especializada no transporte aéreo (nacional e internacional) de animais de companhia. Os questionários foram preenchidos de forma voluntária e anônima por tutores que possuíam no mínimo um cão ou um gato a embarcar.

Participaram do primeiro questionário 80 tutores que efetivamente optaram pelo transporte de seus animais na cabine ou no porão da aeronave junto à empresa, compondo o teste de preferência. O preço do serviço, espécie, raça e tamanho do animal não limitaram a escolha pelo modo de transporte, somente o desejo do tutor em manter o pet em sua companhia ou não durante o traslado, uma vez que o valor cobrado foi o mesmo para ambas as opções e aos animais de médio a grande porte não houveram restrições quanto a serem transportados na cabine, haja visto que foram classificados como animais de assistência emocional.

O segundo questionário foi aplicado a 157 indivíduos que possuíam ao menos a intenção de viajar de avião com um ou mais de seus animais de companhia. As perguntas foram fechadas de múltipla escolha e versavam sobre a temática em questão, distribuídas em três seções.

Seção 1: Uma escala hedônica de 1 a 7 (1 - extremamente despreocupante a 7 - extremamente preocupante) compôs as opções de respostas para cada pergunta, consistindo de questões relacionados ao grau de preocupação do tutor em relação ao bem-estar de seu animal durante o traslado, são elas: animal se sentir mal, animal se acidentar, animal sentir fome e sede, animal sentir calor ou frio extremo, animal ser mal tratado e animal não se adaptar à caixa de transporte

Seção 2: Uma escala hedônica de 1 a 7 (1 - extremamente seguro a 7 - extremamente inseguro) compôs as opções de respostas para cada pergunta relacionada às observâncias na contratação do serviço de transporte dos animais de companhia, são elas: restrições quanto ao tamanho, peso e raça, burocracia na documentação expedida, transporte isolado (sem a companhia do tutor), impedimento de recebimento do animal no embarque/desembarque e extravio.

Seção 3: Uma escala hedônica de 1 a 3 (1 - pouco importante a 3 - muito importante) compôs as opções de resposta para cada pergunta relacionada à infraestrutura do aeroporto/companhia aérea para receber animais de companhia, a seguir: presença de espaço físico pet friendly, certificação pet friendly e garantia de bem-estar animal/segurança durante a viagem.

Todos os participantes proveram seu consentimento de participação e foram brevemente informados sobre a pesquisa 
antes de responder aos questionários. Não foram coletados quaisquer dados confidenciais ou identificadas informações de qualquer natureza dos participantes. O conteúdo dos questionários foi elaborado pelos autores, sem qualquer intenção de avaliar a personalidade ou características dos entrevistados.

O foco do estudo foi único e exclusivamente avaliar a preferência do tutor pelo modo com que seus animais de companhia seriam transportados em voos comerciais coletivos e suas percepções em relação ao traslado. Nenhum animal foi utilizado ou submetido a quaisquer formas de ensaio científico ou protocolo experimental. Dessa forma, o parecer ético não se fez necessário.

Os dados obtidos foram tabulados, analisados sua frequência e submetidos ao teste qui-quadrado para avaliar a independência das variáveis, pelo procedimento FREQ do pacote de análises estatísticas SAS, versão 9.0 (SAS, 2002).

\section{Resultados e Discussão}

Como resultado do teste de preferência, verificamos que 58\% $(n=46)$ dos tutores optaram por embarcar seus pets na cabine de passageiros e $42 \%(n=34)$ no porão da aeronave $(\chi 2=11,7 ; p$-valor $=0,0002)$, conforme apresentado na Figura 1.

Figura 1. Preferência dos tutores $(\mathrm{n}=80)$ ao transportar animais de companhia em voos comerciais.

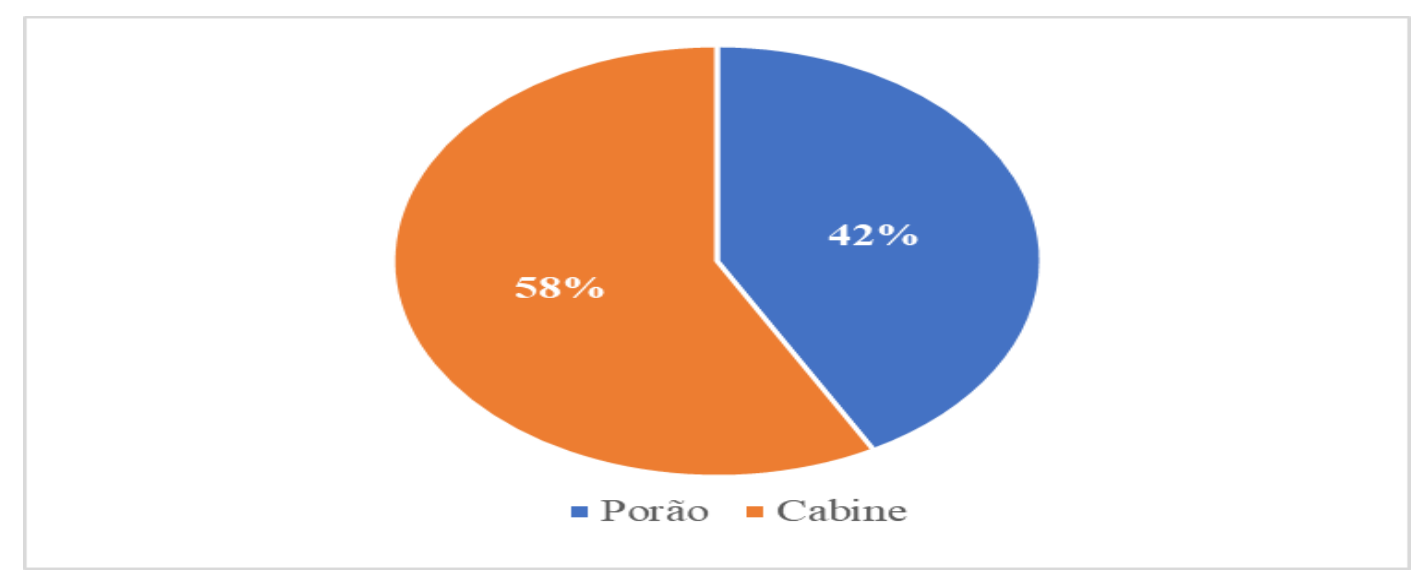

$\chi^{2}=11,7 ;$-valor $=0,0002$. Fonte: Autores 
O fato da maior parte dos tutores preferirem que seus animais sejam transportados nas cabines, e não despachados como carga viva em voos comerciais, certamente é reflexo da ausência de alinhamento comum acerca das boas práticas de transporte adotadas nos aeroportos nacionais e internacionais, em consonância com as linhas aéreas, associado aos inúmeros casos já denunciados pelo Ministério Público de animais extraviados, transportados em condições precárias e que, por vezes, vieram a óbito nos porões das aeronaves, caracterizando crime ambiental e de maus-tratos, uma vez que não há legislação nacional específica que verse sobre o transporte comercial aéreo de animais domésticos. Sendo assim, a maioria dos tutores optam por transportar seus animais de estimação na cabine, próximos de si, pois se sentem mais seguros, menos preocupados e atentos a quaisquer intercorrências que possam ocorrer durante o voo, conforme podemos constatar com os resultados obtidos a partir do segundo questionário, como evidenciado na Tabela 1.

Tabela 1. Grau de preocupação do tutor em relação ao bem-estar do seu animal durante o transporte aéreo [n (\%)]*.

\begin{tabular}{|c|c|c|c|c|c|c|c|c|c|c|}
\hline Itens & 1 & 2 & 3 & 4 & 5 & 6 & 7 & $\mathrm{~N}$ & $\chi^{2}$ & $\mathrm{p}$-valor \\
\hline Animal se sentir mal & $\begin{array}{c}6 \\
(3,8 \%)\end{array}$ & $\begin{array}{c}6 \\
(3,8 \%)\end{array}$ & $\begin{array}{c}10 \\
(6,4 \%)\end{array}$ & $\begin{array}{c}6 \\
(3,8 \%)\end{array}$ & $\begin{array}{c}12 \\
(7,7 \%)\end{array}$ & $\begin{array}{c}10 \\
(6,4 \%)\end{array}$ & $\begin{array}{c}106 \\
(67,9 \%)\end{array}$ & 156 & 10,2 & 0,0234 \\
\hline Animal se acidentar & $\begin{array}{c}10 \\
(6,5 \%)\end{array}$ & $\begin{array}{c}6 \\
(3,9 \%)\end{array}$ & $\begin{array}{c}13 \\
(8,4 \%)\end{array}$ & $\begin{array}{c}7 \\
(4,5 \%)\end{array}$ & $\begin{array}{c}4 \\
(2,6 \%)\end{array}$ & $\begin{array}{c}9 \\
(5,8 \%)\end{array}$ & $\begin{array}{c}105 \\
(68,2 \%)\end{array}$ & 154 & 13,2 & 0,0121 \\
\hline Animal sentir fome e sede & $\begin{array}{c}5 \\
(3,2 \%)\end{array}$ & $\begin{array}{c}12 \\
(7,7 \%)\end{array}$ & $\begin{array}{c}8 \\
(5,2 \%)\end{array}$ & $\begin{array}{c}9 \\
(5,8 \%)\end{array}$ & $\begin{array}{c}10 \\
(6,5 \%)\end{array}$ & $\begin{array}{c}16 \\
(10,3 \%)\end{array}$ & $\begin{array}{c}95 \\
(61,3 \%)\end{array}$ & 155 & 12,2 & 0,0234 \\
\hline $\begin{array}{l}\text { Animal sentir calor ou frio } \\
\text { extremo }\end{array}$ & $\begin{array}{c}23 \\
(15,0 \%)\end{array}$ & $\begin{array}{c}16 \\
(10,5 \%)\end{array}$ & $\begin{array}{c}13 \\
(8,5 \%)\end{array}$ & $\begin{array}{c}16 \\
(10,5 \%)\end{array}$ & $\begin{array}{c}2 \\
(15,0 \%)\end{array}$ & $\begin{array}{c}16 \\
(10,5 \%)\end{array}$ & $\begin{array}{c}46 \\
(30,1 \%)\end{array}$ & 153 & 11,2 & 0,0004 \\
\hline Animal ser maltratado & $\begin{array}{c}3 \\
(1,9 \%)\end{array}$ & $\begin{array}{c}8 \\
(5,1 \%)\end{array}$ & $\begin{array}{c}5 \\
(3,2 \%)\end{array}$ & $\begin{array}{c}7 \\
(4,5 \%)\end{array}$ & $\begin{array}{c}7 \\
(4,5 \%)\end{array}$ & $\begin{array}{c}10 \\
(6,4 \%)\end{array}$ & $\begin{array}{c}116 \\
(74,4 \%)\end{array}$ & 156 & 9,2 & 0,0032 \\
\hline $\begin{array}{l}\text { Animal não se adaptar à } \\
\text { caixa de transporte }\end{array}$ & $\begin{array}{c}16 \\
(10,3 \%)\end{array}$ & $\begin{array}{c}9 \\
(5,8 \%)\end{array}$ & $\begin{array}{c}13 \\
(8,3 \%)\end{array}$ & $\begin{array}{c}10 \\
(6,4 \%)\end{array}$ & $\begin{array}{c}19 \\
(12,2 \%)\end{array}$ & $\begin{array}{c}20 \\
(12,8 \%)\end{array}$ & $\begin{array}{c}69 \\
(44,2 \%)\end{array}$ & 156 & 15,2 & 0,0067 \\
\hline
\end{tabular}

*Escala hedônica de 1 a 7 (1 - extremamente despreocupante; 7 - extremamente preocupante). Fonte: elaborada pelos autores.

$\mathrm{Na}$ avaliação do grau de preocupação dos tutores, em relação ao bem-estar do animal durante o voo, todos os fatores considerados alcançaram maior frequência hedônica no nível 7 da escala, o correspondente a "extremamente preocupante" (Tabela 1). Neste nível da escala, o medo do animal ser maltratado por funcionários dos aeroportos e/ou das companhias aéreas representou a maior preocupação, correspondendo a $74,4 \%$ das respostas, seguido pela preocupação com a ocorrência de acidentes $(68,2 \%)$, com a possibilidade de se sentirem mal fisicamente $(67,9 \%)$, de sentirem fome e/ou sede (61,3\%), de não se adaptarem às caixas transportadoras $(44,2 \%)$ e de sentirem frio ou calor extremo $(30,1 \%)$, respectivamente.

Essa extrema preocupação por parte dos tutores é legítima, uma vez que Collins et al. (2020) descreveram em sua mais recente revisão sobre o transporte aéreo de bovinos, e que pode ser extrapolada para animais de companhia transportados em voos comerciais, os principais pontos críticos relacionados ao bem-estar animal já identificados durante o voo, entre eles, a privação de alimentos e água, especialmente quando o embarque atrasa, o manejo e o acesso dificultados aos animais em 
trânsito, os efeitos da turbulência (Otarola, 2018), a inadequação da temperatura, ventilação (Alliance Consulting and Management, 2001) e das caixas de transporte (Hogan \& Willis, 2009), a falta de planejamento de contingência, considerando a eutanásia de emergência (Australian Government, 2020), e a identificação das raças de alto risco, como as braquicefálicas no caso dos cães. É também evidente a necessidade de maior transparência das práticas adotadas durante o transporte aéreo, para correção das falhas sistêmicas e determinação de outros fatores de risco para mortalidade e morbidade dos animais.

Em um dos poucos estudos realizados em voos comerciais com animais de companhia, Bergeron et al. (2002), ao monitorarem por vídeo o comportamento de cães da raça Beagle, transportados por 48 minutos no porão de carga de um Boeing 757-200, sugeriram que esse modo de transporte possa ser bastante estressante para os animais, sobretudo no embarque e desembarque, haja vista a frequência cardíaca significativamente mais alta nesta etapa (180 batimentos/min) quando comparada às demais: decolagem, voo em si e aterrisagem ( 80 - 90 batimentos/min). Os autores também relataram que os animais permaneceram mais de $50 \%$ do tempo da viagem deitados e o restante do tempo sentados. Além disso, os cães permaneceram inativos por mais de $75 \%$ do tempo, exceto na decolagem. Também não demonstraram sinais de excitação, como cavar, raspar ou latir, tampouco de comportamentos estereotipados, como lamber a boca e o focinho repetidas vezes, levantar as patas e tremer o corpo.

Já Venable et al. (2016) ao avaliarem o comportamento de cães transportados por 2,5h na cabine de aeronaves comerciais, não detectaram diferenças significativas quando comparados ao grupo controle, também mantido em caixas de transporte, mas em solo firme. Entretanto, os animais transportados nas cabines apresentaram fezes mais macias, com parâmetros sanguíneos e composição da microbiota gastrointestinal alterados, indicando, de igual forma, efeito do estresse quando utilizado esse método de transporte.

O fato é que, independentemente do método de transporte escolhido pelo tutor, há que se compreender que os animais têm seus direitos claramente expressos na Constituição Federal (1988), art. $5^{\circ}$ que trata do direito à vida e art. $225, \S 1^{\circ}$, VII, que incumbe ao Poder Público proteger a fauna e a flora, vedada na forma da lei as práticas que submetam os animais à crueldade, na Lei Federal n. 9.605 (1998), conhecida como Lei dos Crimes Ambientais, nas legislações estaduais e municipais, bem como na Declaração Universal dos Direitos dos Animais, que defende o direito à vida, contra os maus tratos e ao ato que ponha em risco suas vidas. Esses são direitos previstos por lei e cotidianamente inobservados pelas companhias aéreas, que se esquivam de sua responsabilidade, observadas as escassas regulamentações, lacunas nas leis e inexistente fiscalização (Souza \& Paoli, 2019).

Já em relação à sensação de segurança na aquisição dos serviços de transporte aéreo, os tutores demonstraram "extrema insegurança" para todos os fatores considerados, representados pelo maior número de respostas no nível 7 da escala hedônica, conforme demonstrado na Tabela 2. Dentro deste nível, merecem destaque a "extrema insegurança" dos tutores em relação à possibilidade de extravio de seus animais, correspondendo a 76,0\% das respostas, seguido pela "extrema insegurança" de permitirem que seus pets viajem sozinhos $(65,4 \%)$ e da possibilidade de serem impedidos [os animais] de embarcarem ou desembarcarem nos aeroportos $(62,1 \%)$, respectivamente. As restrições quanto ao tamanho, peso e raça dos animais e a burocracia na documentação exigida para o transporte aéreo, apresentaram as menores frequências dentro do nível 7, mas ainda assim, foram considerados fatores de "extrema insegurança" pelos tutores, correspondendo a 44,5\% e 43,2\% das respostas, respectivamente. 
Tabela 2. Grau de insegurança do tutor referente às observâncias na contratação dos serviços de transporte aéreo para animais de companhia [n (\%)].*

\begin{tabular}{|c|c|c|c|c|c|c|c|c|c|c|}
\hline Itens & 1 & 2 & 3 & 4 & 5 & 6 & 7 & $\mathrm{~N}$ & $\chi^{2}$ & $\begin{array}{c}\mathrm{p}- \\
\text { valor }\end{array}$ \\
\hline $\begin{array}{l}\text { Restrições quanto ao } \\
\text { tamanho, peso e raça } \\
\text { do pet }\end{array}$ & $\begin{array}{c}23 \\
(14,8 \%)\end{array}$ & $\begin{array}{c}14 \\
(9,0 \%)\end{array}$ & $\begin{array}{c}7 \\
(4,5 \%)\end{array}$ & $\begin{array}{c}16 \\
(10,3 \%)\end{array}$ & $\begin{array}{c}12 \\
(7,7 \%)\end{array}$ & $\begin{array}{c}14 \\
(9,0 \%)\end{array}$ & $\begin{array}{c}69 \\
(44,5 \%)\end{array}$ & 155 & 12,2 & 0,0002 \\
\hline $\begin{array}{l}\text { Burocracia na } \\
\text { documentação } \\
\text { expedida }\end{array}$ & $\begin{array}{c}13 \\
(8,4 \%)\end{array}$ & $\begin{array}{c}16 \\
(10,3 \%)\end{array}$ & $\begin{array}{c}6 \\
(3,9 \%)\end{array}$ & $\begin{array}{c}10 \\
(6,5 \%)\end{array}$ & $\begin{array}{c}18 \\
(11,6 \%)\end{array}$ & $\begin{array}{c}25 \\
(16,1 \%)\end{array}$ & $\begin{array}{c}67 \\
(43,2 \%)\end{array}$ & 155 & 12,3 & 0,0012 \\
\hline $\begin{array}{l}\text { Transporte isolado } \\
\text { (sem a companhia do } \\
\text { tutor) }\end{array}$ & $\begin{array}{c}4 \\
(2,6 \%)\end{array}$ & $\begin{array}{c}11 \\
(7,1 \%)\end{array}$ & $\begin{array}{c}6 \\
(3,8 \%)\end{array}$ & $\begin{array}{c}6 \\
(3,8 \%)\end{array}$ & $\begin{array}{c}12 \\
(7,7 \%)\end{array}$ & $\begin{array}{c}15 \\
(9,6 \%)\end{array}$ & $\begin{array}{c}102 \\
(65,4 \%)\end{array}$ & 156 & 10,1 & 0,0014 \\
\hline $\begin{array}{l}\text { Impedimento de } \\
\text { recebimento do animal } \\
\text { no embarque e/ou } \\
\text { desembarque }\end{array}$ & $(6,5 \%)$ & $(2,6 \%)$ & $(5,2 \%)$ & $(3,3 \%)$ & $(13,1 \%)$ & $(7,2 \%)$ & $\begin{array}{c}95 \\
(62,1 \%)\end{array}$ & 153 & 11,1 & 0,0004 \\
\hline Extravio & $\begin{array}{c}12 \\
(7,8 \%)\end{array}$ & $\begin{array}{c}3 \\
(1,9 \%)\end{array}$ & $\begin{array}{c}8 \\
(5,2 \%)\end{array}$ & $\begin{array}{c}7 \\
(4,5 \%)\end{array}$ & $\begin{array}{c}2 \\
(1,3 \%)\end{array}$ & $\begin{array}{c}5 \\
(3,2 \%)\end{array}$ & $\begin{array}{c}117 \\
(76,0 \%)\end{array}$ & 154 & 16,1 & 0,0067 \\
\hline
\end{tabular}

*Escala hedônica de 1 a 7 (1 - extremamente seguro; 7 - extremamente inseguro). Fonte: Autores.

Tamanha insegurança parte do descaso, da omissão e da negligência observada durante o transporte dos animais, os quais são rotineiramente tratados como bagagem (Bland, 2013), o que faz com que muitos tutores busquem por agências de viagens especializadas no transporte aéreo de animais pet, as quais fornecem serviços como consultoria de viagem pet, emissão de certidões e laudos veterinários, e assistência completa ao tutor desde o momento do embarque ao desembarque de seus animais, a fim de assegurar que seus pets tenham garantido o mínimo de conforto e bem-estar durante todo o transporte, além de assegurada sua recepção em seu destino final.

Essa preocupação é refletida na avaliação do grau da importância dada pelo tutor à infraestrutura dos aeroportos e linhas aéreas (Tabela 3), quando todos os fatores alcançaram maior frequência hedônica no nível 3 da escala, o correspondente a "muito importante". Neste nível da escala, a garantia do bem-estar animal/segurança foi considerada de maior importância, com $91,1 \%$ das respostas, seguida pela importância dada à presença de espaço físico pet friendly $(70,7 \%)$ e à certificação pet friendly $(63,7 \%)$, respectivamente. 
Tabela 3. Grau de importância dado pelo tutor à infraestrutura do aeroporto/companhia aérea para recebimento dos animais de companhia $[\mathrm{n}(\%)]$ *

\begin{tabular}{|c|c|c|c|c|c|c|}
\hline Itens & 1 & 2 & 3 & $\mathrm{~N}$ & $\chi^{2}$ & $\mathrm{p}$-valor \\
\hline Presença de espaço físico pet friendly & $11(7,0 \%)$ & $35(22,3 \%)$ & $111(70,7 \%)$ & 157 & 13,7 & 0,0002 \\
\hline Certificação pet friendly & $25(15,9 \%)$ & $32(20,4 \%)$ & $100(63,7 \%)$ & 157 & 14,5 & 0,0012 \\
\hline Garantia de bem-estar animal/segurança & $2(1,3 \%)$ & $12(7,6 \%)$ & $143(91,1 \%)$ & 157 & 10,9 & 0,0067 \\
\hline
\end{tabular}

*Escala hedônica de 1 a 3 (1 - pouco importante; 3 - muito importante). Fonte: Autores.

Fica evidente a real necessidade e o anseio por melhorias na infraestrutura aeroportuária, desde o espaço físico destinado aos animais que aguardam pelo embarque, quanto à implementação de programas de boas práticas de transporte e bem-estar animal, com certificações e capacitação técnica de toda a equipe envolvida, de modo a atender com qualidade e segurança as diferentes demandas em todas as etapas do transporte aéreo dos animais.

Essas recentes transformações experimentadas na relação humano-animal têm fundamentado as bases para a instituição do Direito Animal, por meio dos princípios da Afetividade, Humanitarismo e Igual Consideração, que versam sobre o afeto que norteia a interação humano-animal, o tratamento dos animais de forma humanista e humanitária e a consciência de mesmos deveres e direitos aos homens e animais, respectivamente; os quais merecem ser considerados em todas as esferas de nossa sociedade, sobretudo nos meios de transporte coletivo que envolvam essa interação do homem com o animal. Ademais, há que se atentar e fazer valer a Lei n. 8.078 (1990), que versa sobre o direito do consumidor, justamente por se tratar de uma relação comercial, mediante o pagamento de contraprestação (bilhete aéreo e/ou bagagem extra), sendo dever das empresas transportadoras zelarem tanto pela segurança, conforto e bem-estar do animal, quanto do seu tutor, razão pelas quais possuem responsabilidade jurídica, caso haja alguma intercorrência no traslado dos animais (Souza \& Paoli, 2019).

Pela dignidade, pelo bem-estar, pela saúde física e mental e pela vida dos animais de companhia, reivindica-se, urgentemente, tratamento ético, moral e digno para aqueles que são transportados via aérea, haja visto que os animais são seres sencientes, com interesses e direitos, uma vez que já foram reconhecidos como sujeitos de direitos, por meio da aprovação do Projeto de Lei da Câmara n. 27 (2018) - “Animal não é coisa”, que acrescenta dispositivo à Lei n 9.605 (1988), para dispor sobre a natureza jurídica dos animais não humanos.

Recomenda-se, portanto, que o tutor colete toda a informação necessária antes de embarcar seu pet, por meio de pesquisa minuciosa sobre as condições de transporte oferecidas pelas diferentes companhias aéreas, optando por aquela que melhor se adeque às necessidades de seu animal de companhia.

\section{Conclusão}

Os tutores preferem transportar seus animais de companhia na cabine das aeronaves, como forma de assegurar o bemestar animal durante o voo. Entretanto, demonstram extrema insegurança e preocupação com os procedimentos de transporte adotados pelas companhias aéreas para com os pets em voos comerciais, além de considerarem muito importante o atendimento às novas demandas por certificações pet friendly e de bem-estar animal nos aeroportos; o que serve como incentivo e abre um novo horizonte para que mais estudos sejam desenvolvidos sobre o comportamento e o bem-estar de animais domésticos sob diferentes condições de transporte aéreo, de forma a garantir melhora contínua em todo o processo e 
assegurar a manutenção da saúde física e emocional desses animais durante o voo.

\section{Agradecimentos}

Agradecemos à PETFriendly Turismo pela colaboração no estudo desenvolvido.

\section{Referências}

Alliance Consulting and Management. (2001). Influence of pre-delivery management of livestock performance: desk top study (LIVE.104A). North Sydney, Australia: Meat and Livestock.

Australian Government. (2020). Australian standards for the export of livestock 3.0. Department of Agriculture, Water and the Environment. Australian Government: Canberra, Australia.

Bergeron, R., Scott, S. L., Emond, J. P., Mercier, F., Cook, N. J., \& Schaefer, A. L. (2002). Physiology and behavior of dogs during air transport. Canadian journal of veterinary research $=$ Revue canadienne de recherche veterinaire, 66(3), 211-216.

Bland, A. (2013). Is taking your pet on an airplane worth the risk. https://www.smithsonianmag.com/travel/is-taking-your-pet-on-an-airplane-worth-the-risk$6241533 /$

Collins, T., Stockman, C., Hampton, J. O., \& Barnes, A. (2020). Identifying animal welfare impacts of livestock air transport. Australian Veterinary Journal, 98(5), 197-199.

Constituição da República Federativa do Brasil, de 05 de outubro de 1988. (1988). Brasília, DF. http://www.planalto.gov.br/ccivil_03/constituicao/constit uicao.htm

Coren, S. (2012). Is it safe to ship dogs or cats by air? Recuperado de https://www.psychologytoday.com/intl/blog/canine-corner/201209/is-it-safe-ship-dogsor-cats-air?

Escobar-Aguirre, S., Alegría-Morán, R. A., Calderón-Amor, J., \& Tadich, T. A. (2019). Can Responsible Ownership Practices Influence Hunting Behavior of Owned Cats? Results from a Survey of Cat Owners in Chile. Animals, 9(10), 745.

Fleming, P. A., Wickham, S. L., Dunston-Clarke, E. J., Willis, R. S., Barnes, A. L., Miller, D. W., \& Collins, T. (2020). Review of Livestock Welfare Indicators Relevant for the Australian Live Export Industry. Animals, 10(7), 1236.

Hogan, L., \& Willis, G. (2009). Best practice design of crates for livestock export by air. North Sydney, Australia: Meat and Livestock Australia

Lei n. 8.078, de 11 de setembro de 1990. (1990). Dispõe sobre a proteção do consumidor e dá outras providências. Brasília, DF. Recuperado de http://www.p lanalto.gov.br/ccivil_03/leis/18078compilado.htm

Lei Federal n. 9.605, de 12 de fevereiro de 1998. (1998). Dispõe sobre as sanções penais e administrativas derivadas de condutas e atividades lesivas ao meio ambiente, e dá outras providências. Brasília, DF. http://www.planalto.gov.br/ccivil_03/leis/19605.htm

Menchetti, L., Calipari, S., Mariti, C., Gazzano, A., \& Diverio, S. (2020) Cats and dogs: Best friends or deadly enemies? What the owners of cats and dogs living in the same household think about their relationship with people and other pets. PLoS ONE, 15(8), e0237822.

Miguel, P. A. C., Fleury, A., Mello, C. H. P., Nakano, D. N., Turrioni, J. B., Ho, L. L. Pureza, V. (2010). Metodologia de pesquisa em engenharia de produção e gestão de operações. Rio de Janeiro: Elsevier.

Otarola, G. N. (2018). Behavioral and physiological responses of livestock to simulated and actual transport by sea (Tese de Doutorado). University of Queensland, Brisbane, Australia.

Paolini, A., Romagnoli, S., Nardoia, M., Conte, A., Salini, R., Podaliri Vulpiani, M., \& Dalla Villa, P. (2020). Study on the Public Perception of "CommunityOwned Dogs" in the Abruzzo Region, Central Italy. Animals, 10(7), 1227.

Projeto de Lei da Câmara n. 27, de 2018. (2018). Acrescenta dispositivo à Lei $\mathrm{n}^{\circ}$ 9.605, de 12 de fevereiro de 1998, para dispor sobre a natureza jurídica dos animais não humanos. Brasília, DF. https://www25.senado.leg.br/web/atividade/materias/-/materia/133167/pdf

SAS. (2012). Statistical Analysis System user's guide. SAS Institute. Version 9.2, Cary.

Silva, P. H, Moura, W. S., Oliveira, Y. R, Abreu, M. C., Silva, E. L., Ferreira, P. M. P., \& Pacheco, A. C. L. (2020). Level of knowledge of biology students from universidade federal do piauí on the welfare of small domestic animals (dogs and cats). Research, Society and Development, 9(7): 1-18, e324974192.

Souza, J. S., \& Paoli, L. (2019). Transporte de animais de estimação. Será que estamos no caminho certo? https://www.petfriendlyturismo.com.br/2019 /08/16/transporte-de-animais-de-estimacao-sera-que-estamos-no-caminho-certo/

Venable, E. B, Bland, S. D, Holscher, H. D, \& Swanson, K. S. (2016). Effects of air travel stress on the canine microbiome: a pilot study. International Journal of Veterinary Health Science \& Research, 4, 132-139. 